\title{
Segmentasi Pasar Ganda dalam Konser Malam Gembira: Merayakan Karya Cipta Guruh Soekarno Putra
}

\author{
Gisela Anindita \\ Program Pascasarjana Institut Seni Indonesia Yogyakarta \\ gisellaaninditaa@gmail.com
}

\begin{abstract}
Abstrak
Komunikasi marketing adalah sebuah strategi dalam penyampaian informasi mengenai sebuah produk, jasa, ataupun kegiatan. Dalam komunikasi marketing, salah satu hal terpenting ialah segmentasi pasar. Target komunikasi dapat dibagi melalui demografis dan psikologis. Dalam artikel ini akan mendeskripsikan bagaimana ambiguitas target komunikasi marketing dapat terjadi pada Konser Malam Gembira: Merayakan Karya Cipta Guruh Soekarno Putra (KMG) pada tahun 2017. Secara garis besar, target komunikasi marketing KMG terbagi menjadi dua yakni generasi X (kelahiran 1961-1980) dan generasi peralihan Y (1981-1997) dan Z (1998-2011). Hasilnya adalah karena adanya pengaruh perbedaan generasi dalam manajemen KMG itu sendiri. Nama Guruh Soekarno Putra, konsep acara, dan media sosial yang digunakan dalam strategi komunikasi marketing pun menimbulkan ambiguitas, sehingga target market yang dicapai terlalu luas dan menimbulkan ketidak-teraturan pada saat acara tersebut.
\end{abstract}

Kata kunci: target komunikasi marketing, media komunikasi, ambiguitas

\begin{abstract}
Marketing communication is a strategy to give information about a product, service, or any activity. In marketing communication, one of the most important thing is a market segmentation. Communication target audience can be devided by demographic and psychology. This article will be describe about how ambiguity of communication target audience on Konser Malam Gembira: Merayakan Karya Cipta Guruh Soekarno Putra (KMG) 2017 can be occur. In larger scale, communication target audience $K M G$ divide in to two, the $X$ generation (born between 1961-1980) and transitional generation between $Y$ (born between 19811997) and Z (1998-2011). The result found that the ambiguity is occur because of differencess between both generation inside the KMG organization itself. The name of Guruh Soekarno Putro, the concept of the concert, an social media that used in marketing communication strategy also make a ambiguity, thus maket the marketing target too widely and raises the chaotic at the concert.
\end{abstract}

Keywords: marketing communication target, communication media, ambiguity 


\section{PENDAHULUAN}

Komunikasi marketing adalah salah satu strategi dalam menyebarkan informasi mengenai suatu produk, jasa, maupun kegiatan. Dalam strategi komunikasi marketing, hal yang paling utama ialah target komunikasi. Target komunikasi harus ditetapkan secara spesifik sesuai dengan tujuan objek yang ingin dikomunikasikan. Penentuan target komunikasi marketing dapat diidentifikasi secara demografis dan psikologis. Penentuan target komunikasi berguna dalam menentukan bahasa, visual, maupun media yang akan digunakan dalam menyebarkan informasi. Setiap generasi memiliki bahasa, visual, dan cara atau media yang berbeda dalam memberikan dan menerima informasi. Penggunaan ketiga hal tersebut dapat diibaratkan jika kita sedang berbicara pada orang lain. Penggunaan bahasa dan cara yang digunakan jika kita berbicara dengan generasi $\mathrm{Z}$ pasti berbeda ketika kita berbicara dengan generasi X.

Konser Malam Gembira: Merayakan Karya Cipta Guruh Soekarno Putra yang diadakan di The Pallas, SCBD pada tahun 2017, merupakan salah satu kasus yang menarik karena terdapat perbedaan yang cukup signifikan dalam hal demografis usia. Konser yang menampilkan karya Guruh Soekarno Putra dan memiliki konsep reuni ini, memiliki dua target usia, yakni generasi X (kelahiran 1961-1980) dan generasi peralihan antara Y (kelahiran 1981-1997) dan X (kelahiran 1998-2011). Penentuan target usia tersebut dilatarbelakangi oleh panitia yang juga terbentuk dari dua latar belakang usia tersebut. Panitia pelaksana merupakan generasi peralihan YZ yang mengidolakan Guruh dan menikmati karya-karya Guruh. Sedangkan pelindung acara adalah Guruh dan teman-temannya yang tergolong pada generasi X. Dua latar belakang usia dalam kepanitiaan ini yang menjadi landasan penentuan target komunikasi marketing acara KMG tersebut.

Generasi X merupakan penikmat karya Guruh ketika awal berkarier, hingga akhirnya Guruh memutuskan untuk berhenti. Generasi X mengetahui dan merasakan secara langsung perkembangan musik dan seni pertunjukan yang diciptakan oleh Guruh pada sekitar tahun 1970-1980, sedangkan generasi peralihan YZ menikmati karya Guruh melalui sosial media dan orang tua mereka. Dalam hal ini, generasi peralihan YZ hanya menikmati karya Guruh tanpa mengetahui latar belakang, cerita, maupun polemik yang terjadi ketika karya itu tercipta. Begitu juga dengan seni pertunjukan Swara Gembira, generasi peralihan YZ hanya menyaksikannya melalui sosial media dengan sumber kualitas rekaman gambar yang masih sangat terbatas.

Berdasarkan latar belakang target komunikasi marketing dalam KMG tersebut, penulis ingin mengetahui apa saja yang dihasilkan ketika strategi komunikasi marketing memiliki dua kelompok target komunikasi yang sangat berbeda jika dilihat melalui latar belakang demografis usia.

\section{Kajian Pustaka}

Pada tulisan ini, penulis membahas mengenai target komunikasi marketing. Pada jurnal "The targeted and non-targeted framework: Differential impact of marketing tactics on customer perceptions” (Bang Nguyen, Mo Li, Cheng-Ho (Steve) Chen, 2016) mengatakan bahwa, strategi marketing komunikasi memiliki dua jenis sasaran komunikasi, yakni target dan bukan target. Keduanya memiliki respons yang sangat berbeda. Individu 
yang termasuk ke dalam target ialah mereka yang memiliki kesamaan sifat atau nilai-nilai yang dicerminkan oleh produk tersebut, sedangkan bukan target ialah mereka yang tidak memiliki kesamaan nilai maupun sifat dari produk tersebut.

Kelompok yang dikatakan target cenderung rela untuk membeli produk atau jasa tersebut dan tidak terlalu mempedulikan harga. Respons mereka terhadap produk atau jasa tersebut juga relatif positif. Hal ini berbeda dengan kelompok bukan target. Mereka sangat memerhatikan harga, karena mereka tidak memiliki keinginan untuk membeli produk atau jasa tersebut. Kelompok bukan target akan mengeluarkan usaha sekecil mungkin untuk mendapatkan produk atau jasa tersebut. Respons terhadap produk atau jasa tersebut juga relatif negatif. Ini dikarenakan barang tersebut tidak sesuai dengan harapan mereka. Generasi X tidak memercayai pengorbanan dalam bentuk apapun untuk mendapatkan produk atau jasa yang mereka inginkan. Menurut mereka, apa yang mereka keluarkan harus sesuai dengan apa yang mereka dapatkan.

Pada jurnal "Marketing to the Generations" (Kaylene C. Williams dan Robert A. Page) mengatakan bahwa setiap generasi memiliki harapan, pengalaman, latar belakang sejarah, nilai, dan demografis yang berbeda. Pada jurnal ini dijelaskan bahwa generasi $\mathrm{X}$ memiliki karakteristik seperti kesetiaan pada pekerjaan dan berorientasi pada profesionalitas kerja. Bagi generasi X, keseimbangan antara keluarga, kehidupan pribadi, dan pekerjaan sangatlah penting. Generasi $X$ tidak tertarik pada televisi dan komunikasi melalui media daring karena cenderung akan membuat mereka menjauh. Hal ini berbeda dengan generasi peralihan YZ. Generasi peralihan YZ sangatlah menguasai media daring. Bagi generasi peralihan $\mathrm{YZ}$, batas global menjadi semakin menghilang karena adanya teknologi dan segala sesuatunya menjadi lebih transparan. Generasi peralihan YZ tidak pernah lepas dari media daring. Mereka benar-benar memikirkan produk atau jasa yang sesuai dengan pribadinya dan rela mengeluarkan usaha yang lebih untuk mendapatkan hal tersebut.

Pada jurnal "Communicating with Target Environment" (Stanka Duric dan Svetlana Trejkovic) menjelaskan bahwa, komunikasi merupakan pertukaran informasi di antara dua subjek. Namun, dalam hal bisnis dan marketing, komunikasi seharusnya tidak terjadi hanya sampai pada definisi tersebut. Dalam komunikasi, pemberi informasi sebaiknya menggunakan bahasa, kode, hingga ekspresi yang dimengerti oleh penerima informasi. Sehingga informasi yang diterima dapat tepat dan efektif. Di dalam jurnal ini juga dikatakan bahwa hal yang terjadi pada bisnis hari ini adalah komunikasi yang didasari oleh asumsi pemberi informasi atas penerima informasi.

Sedangkan dalam jurnal "Overcoming the Challenges of Professional Services Marketing” (Jennifer D. Chrzastek dan Cyndy Reid, 2004) mengatakan bahwa dalam menentukan target komunikasi marketing, sebuah produk atau jasa harus menentukan posisi mereka di dalam bidangnya. Setelah menentukan posisi, mereka akan mengetahui kepada bagaimana mereka akan berbicara dan kepada siapa mereka akan berbicara. Hal ketiga yang perlu dilakukan adalah menguasai media yang tepat dalam menyampaikan informasi produk ataupun jasa mereka. Media yang dipilih sebaiknya adalah media yang akrab digunakan oleh para target dan juga sesuai dengan posisi dan apa yang akan disampaikan. Pada jurnal ini diberikan contoh bahwa kampanye untuk tidak menggunakan gawai secara berlebihan kepada para remaja, namun dalam kampanyenya menggunakan 
sosial media. Menurut jurnal ini, hal ini dipandang bertentangan dengan informasi yang ingin disampaikan pada kampanye tersebut.

Berdasarkan ketiga jurnal tersebut, penulis ingin meneliti bagaimana strategi komunikasi marketing yang memiliki perbedaan generasi target komunikasi bekerja pada studi kasus Konser Malam Gembira: Merayakan Karya Cipta Guruh Soekarno Putra. Bagaimana hasil dari perbedaan generasi target komunikasi dalam konser tersebut.

\section{METODE PENELITIAN}

\section{Pendekatan}

Dalam penelitian ambiguitas target komunikasi marketing ini, penulis menggunakan metode kualitatif agar bisa mengungkapkan permasalahan serta fenomena secara mendalam. Pendekatan pada penelitian ini adalah studi kasus, yang dilakukan pada Konser Malam Gembira: Merayakan Karya Cipta Guruh Soekarno Putra.

\section{Teknik Pengumpulan Data}

Penulis menggunakan teknik pengumpulan data melalui wawancara. Wawancara terhadap informan secara mendalam dianggap mampu untuk menemukan cara pandang dan cara berpikir mengenai penentuan target dan strategi komunikasi marketing pada studi kasus tersebut.

Wawancara yang dilakukan adalah wawancara semi terstruktur dengan mengajukan beberapa pertanyaan awal untuk memulai pertanyaan-pertanyaan yang disampaikan secara spontan dengan merespons jawaban informan. Penulis merancang suasana wawancara dalam situasi tidak formal agar informan dapat secara nyaman menyampaikan pengalaman dan juga pemikirannya mengenai kasus tersebut dan juga strategi dan tujuannya dalam memutuskan strategi yang dipilih. Pertanyaan-pertanyaan yang diajukan bersifat untuk menggali pemikiran, pengalaman, dan juga strategi marketing secara teratur berdasarkan periode waktu. Pertanyaan dibagi menjadi tiga hal tersebut, sehingga walaupun berjalan secara spontan, tetap dapat membantu penulis untuk mengodekan setiap jawaban sesuai dengan kelompoknya.

Alat bantu yang digunakan oleh penulis adalah alat perekam berupa gawai. Alat perekam menggunakan gawai memiliki kekurangan kejernihan suara yang kurang baik. Sehingga banyak suara yang tidak penting terekam pada percakapan. Penulis juga menggunakan spidol dan buku catatan untuk mencatat beberapa ekspresi wajah, gerak, dan beberapa istilah-istilah yang penting dan berpengaruh pada jawaban verbal informan.

\section{Narasumber}

Dalam penelitian kualitatif, penulis adalah instrumen paling penting dalam penelitian yang akan langsung berhubungan dengan pihak-pihak yang terkait dengan objek penelitian. Pihak-pihak yang dipilih oleh penulis adalah yang dipandang memiliki kompetensi dan pemahaman mengenai permasalahan penelitian.

Narasumber dalam penelitian ini adalah orang-orang yang mempunyai peran dalam menentukan bentuk acara, target komunikasi marketing, dan harga. Narasumber 
yang penulis wawancarai adalah Ketua Panitia Pelaksana KMG, Muhammad Khoirul dan juga Panitia Pelindung acara tersebut, yakni Guruh Soekarno Putra.

\section{Waktu dan Lokasi Wawancara}

Wawancara kepada para target komunikasi marketing dilakukan di The Pallas, SCBD, Jakarta pada tanggal 15 Agustus 2017. Sedangkan wawancara kepada panitia dan Guruh Soekarno Putra dilakukan di The Pallas, SCBD, Jakarta pada tanggal 14 Agustus 2017.

\section{HASIL DAN PEMBAHASAN}

Target komunikasi marketing merupakan hal penting dalam menentukan strategi komunikasi marketing. Dalam KMG yang memiliki dua kelompok besar generasi yang menjadi target komunikasi marketing. Namun hal tersebut menemui kesulitan dikarenakan kedua generasi tersebut memiliki perbedaan yang cukup besar pada latar belakang dan pengalaman.

Menurut data-data yang diperoleh, penulis membagi menjadi dua garis besar mengenai bagaimana ambiguitas target komunikasi marketing pada KMG dapat terjadi dan hal-hal apa yang memengaruhi ambiguitas target komunikasi marketing.

\section{Pengolahan informasi generasi $X$ dan peralihan $Y Z$ berbeda}

Penyampaian informasi sangatlah penting pada sebuah strategi komunikasi marketing. Pada kasus ini, panitia pelaksana yang berperan sebagai informan menyampaikan informasi yang sama mengenai waktu, tempat, dan penampil kepada para target komunikasi pada dua generasi, yakni $\mathrm{X}$ dan peralihan YZ. Sedangkan informasi harga yang disampaikan berbeda kepada kedua generasi tersebut. Generasi X mendapat informasi harga yang beberapa kali lebih besar dibanding generasi peralihan YZ.

Dalam mengolah informasi media dan cara informan dalam menyampaikan informasi juga memberikan pengaruh kepada target. Pada acara KMG, informan menyampaikan informasi melalui dua cara yang berbeda kepada dua generasi yang juga dapat memengaruhi informasi yang diterima oleh kedua generasi tersebut. Generasi X mendapatkan informasi melalui informan dalam bentuk formal seperti undangan berbentuk fisik. Dan target market yang ada pada generasi X kurang lebih ialah kolega dari Guruh Soekarno Putra itu sendiri. Sedangkan generasi X lainnya mengetahui informasi tersebut melalui generasi peralihan YZ, yang merupakan anak mereka.

Generasi peralihan YZ sendiri mendapatkan informasi melalui media daring. KMG hanya menggunakan satu media daring untuk melakukan strategi marketing, yakni sosial media Instagram. Selain itu, penyebaran informasi kepada generasi peralihan YZ dilakukan secara mouth-to-mouth melalui panitia pelaksana yang juga adalah generasi tersebut. Penyebaran informasi yang terjadi pada generasi peralihan YZ juga berlangsung cepat dan terjadi pada skala yang besar.

Maka berdasarkan dua hal tersebut, hasil informasi yang diolah oleh setiap generasi berbeda. Pengolahan informasi dipengaruhi oleh informasi yang disampaikan itu sendiri, 
media atau cara penyampaian, dan pengalaman yang berbeda dari masing-masing generasi tersebut. Generasi X mengolah informasi yang didapat dengan menggabungkan dengan pengalamannya pada masa kejayaan Guruh Soekarno Putra (1977-1989). Seni pertunjukan Guruh Soekarno Putra yang pada masa itu memiliki reputasi sangat baik, membuat generasi X memiliki harapan bahwa KMG akan sama seperti seni pertunjukan Guruh Soekarno pada masa itu. Sedangkan generasi peralihan XY mengolah informasi secara literal sesuai dengan bahasa dan visual yang mereka terima. Generasi peralihan XY cenderung tidak memiliki pemikiran mengenai kualitas dari seni pertunjukan Guruh Soekarno Putra pada masa kejayaannya. Dalam memutuskan untuk menghadiri KMG, generasi peralihan XY mempertimbangkan mengenai popularitas acara KMG.

\section{Penentuan Segmentasi Pasar}

Marketing memiliki beberapa teori mengenai segmentasi pasar yang di dalamnya sama-sama memiliki wacana mengenai target dan bukan target komunikasi marketing ataupun target primer dan sekunder. Keduanya sama-sama meyakini bahwa kelompok yang disebut sebagai target adalah prioritas dan landasan strategi komunikasi marketing tersebut dirancang. Sedangkan kelompok bukan target merupakan mereka yang secara komunikasi tidak termasuk sebagai prioritas. Maka dapat disimpulkan bahwa strategi komunikasi marketing akan efektif jika menetapkan target komunikasi marketing pada satu kelompok.

Hal yang terjadi pada KMG adalah ambiguitas target dan bukan target. KMG memiliki dua kelompok generasi sebagai target komunikasi marketingnya. Jika dilihat dari masing-masing variabel informasi yang disampaikan oleh informan kepada masing-masing kelompok generasi, yang berbeda adalah informasi mengenai harga tiket KMG. Generasi $\mathrm{X}$ mendapatkan informasi harga tiket pada kelas VIP dan sebagai prioritas. Media dan cara penyampaian informasi kepada generasi $\mathrm{X}$ pun dilakukan secara formal dan personal. Berbeda dengan penyampaian informasi kepada generasi YZ yang dilakukan secara besar dan serentak pada sosial media daring. Namun, media penyebaran informasi menggunakan sosial media daring lebih banyak dilakukan oleh informan. Jika generasi X adalah kelompok target, maka penyebaran informasi menggunakan sosial media daring dibatasi. Namun jika generasi YZ adalah kelompok target, maka bentuk acara dan informasi lain mengenai acara disampaikan dengan lebih jelas kepada generasi $\mathrm{X}$.

Maka dari pemaparan di atas, pada KMG terjadi ambiguitas target market yang didasari pada informasi yang disampaikan, dan cara disampaikannya informasi tersebut. Hal ini mengakibatkan KMG ketika personifikasi, memiliki dua identitas, yakni generasi $\mathrm{X}$ dan generasi YZ. KMG tidak memilih salah satu kelompok generasi sebagai identitasnya, sehingga terjadi ambiguitas kelompok target dan bukan target komunikasi marketing.

\section{KESIMPULAN}

Berdasarkan pemaparan dan pembahasan di atas, dapat disimpulkan bahwa ambiguitas target komunikasi marketing pada KMG terjadi karena adanya ambiguitas identitas dan posisi dari KMG itu sendiri. Ambiguitas identitas dan posisi KMG berpengaruh pada informasi yang disampaikan, media, dan cara penyampaian informasi 
mengenai KMG kepada masing-masing kelompok generasi. Kemudian ketiga variabel pada masing-masing generasi diolah berdasarkan pengalaman dan latar belakang masingmasing generasi. Berdasarkan hasil pengolahan informasi tersebut, generasi $\mathrm{X}$ dan peralihan YZ memiliki hasil yang berbeda. Generasi X memiliki harapan, KMG memiliki kualitas yang sama seperti konser Guruh Soekarno Putra pada tahun 1977-1989. Sedangkan generasi peralihan $\mathrm{YZ}$ mengolah informasi secara literal berdasarkan apa yang disampaikan informan. Namun, kedua penyampaian informasi kepada dua kelompok generasi dilakukan secara serentak dalam skala besar. Hal ini juga yang menyebabkan ambiguitas target komunikasi marketing karena tidak adanya pemilihan kelompok target sebagai prioritas.

\section{KEPUSTAKAAN}

Araujo, Luis. 2007. Markets, market-making and marketing. SAGE Publication, Vol. 7(3): 211-226.

Akridge, Jay; Foltz, John; Reimer, Aaron. 2007. Market Segmentation: Making it Work in Your World. Feed \& Grain; Fort Atkinson. Vol. 46, Iss. 6.

Bang Nguyen, Mo Li, Cheng-Ho (Steve) Chen. 2012. Differential impact of marketing tactics on customer perceptions. Journal of Targeting, Measurement and Analysis for Marketing, Vol. 20, 2, 96-108.

Araujo, Luis. 2007. Markets, market-making and marketing. SAGE Publication, Vol. 7(3): 211-226.

Dickson, Peter R; Ginter, James L. 1987. Market segmentation, product differentiation, and marketing strategy. Journal of Marketing. Chicago, Vol. 51, Iss. 2.

Duric, Stanka dan Svetlana Trejkovic. 2006. Communicating with Target Environment. Journal of Process Management - New Technologies, International, Vol. 4, No.3

Lee, Deborah. 2004. Market Research: Market Segmentation and Libraries. Library Administration \& Management. Chicago, Vol. 18, Iss. 1

Lesser, Jack A; Hughes, Marie Adele. 1986. The Generalizability of Psychographic Market Segments across Geographic Locations. Journal of Marketing, Chicago, Vol. 50, Iss. 1

Williams, Kaylene C dan Robert A Page. 2011. Marketing to the Generations. Journal of Behavioral Studies in Business. 